\title{
Functional Organization of Flash-Induced V1 Offline Reactivation
}

\author{
Kenta Funayama, ${ }^{1}$ Nobuhiro Hagura, ${ }^{2,3}$ Hiroshi Ban, ${ }^{2,3}$ and ${ }^{\circ}$ Yuji Ikegaya ${ }^{1,2}$ \\ ${ }^{1}$ Graduate School of Pharmaceutical Sciences, The University of Tokyo, Tokyo 113-0033, Japan, ${ }^{2}$ Center for Information and Neural Networks, National \\ Institute of Information and Communications Technology, Suita City, Osaka 565-0871, Japan, and ${ }^{3}$ Graduate School of Frontier Biosciences, Osaka \\ University, Suita City, Osaka 565-0871, Japan
}

The primary visual cortex exhibits a late, long response with a latency of $>300 \mathrm{~ms}$ and an immediate early response that occurs $\sim 100 \mathrm{~ms}$ after a visual stimulus. The late response is thought to contribute to visual functions such as sensory perception, iconic memory, working memory, and forming connections between temporally separated stimuli. However, how the visual late response is generated and organized is not completely understood. In the mouse primary visual cortex in vivo, we isolated long-delayed responses by using a brief light-flash stimulus for which the stimulus late response occurred long after the stimulus offset and was not contaminated by the instantaneous response evoked by the stimulus. Using whole-cell patch-clamp recordings, we demonstrated that the late rebound response was shaped by a net-balanced increase in excitatory and inhibitory synaptic conductances, whereas transient imbalances were caused by intermittent inhibitory barrage. In contrast to the common assumption that the neocortical late response reflects a feedback signal from the downstream higher-order cortical areas, our pharmacological and optogenetic analyses demonstrated that the late responses likely have a thalamic origin. Therefore, the late component of a sensory-evoked cortical response should be interpreted with caution.

Key words: bottom-up; patch-clamp; top-down; visual cortex

\section{Significance Statement}

The long-delayed responses of neocortical neurons are thought to arise from cortical feedback activity that is related to sensory perception and cognition. The mechanism of neocortical late responses was investigated using multiple electrophysiological techniques and the findings indicate that it actually arises from the thalamus. In addition, during the late response, excitation and inhibition are balanced, but inhibition is dominant in patterning action potentials.

\section{Introduction}

The primary visual cortex (V1) is where light information, which reaches $\mathrm{V} 1$ via the retina and the dorsal lateral geniculate nucleus (dLGN) of the thalamus, classically referred to as the feedforward pathway, first reaches the neocortex (Felleman and Van Essen, 1991; Purves et al., 2001). Through this multisynaptic transmission, V1 neurons respond with a short latency after the presentation of a visual stimulus, which is referred to herein as an early

\footnotetext{
Received May 14, 2016; revised Sept. 23, 2016; accepted Sept. 26, 2016.

Author contributions: K.F. and Y.I. designed research; K.F., N.H., and H.B. performed research; K.F., N.H., and H.B. analyzed data; K.F. and Y.I. wrote the paper.

This work was supported by Grants-in-Aid for Scientific Research A (26250003) and Grants-in-Aid for Scientific Research on Innovative Areas "Mental Time" (25119004) from the Ministry of Education, Culture, Sports, Science and Technology (MEXT).

Correspondence should be addressed to Yuji Ikegaya, Ph.D., Laboratory of Chemical Pharmacology, Graduate School of Pharmaceutical Sciences, The University of Tokyo, 7-3-1 Hongo, Bunkyo-ku, Tokyo 113-0033, Japan. E-mail:yuj@ikegaya.jp.

DOI:10.1523/JNEUROSCI.1575-16.2016

Copyright $\odot 2016$ the authors $\quad 0270-6474 / 16 / 3611727-12 \$ 15.00 / 0$
}

response. Studies have mostly targeted this immediate early response for which the basic properties are well described (Ohki et al., 2005; Niell and Stryker, 2008; Priebe and Ferster, 2008; Jia et al., 2010; Hofer et al., 2011; Liu et al., 2011). More recently, the delayed component of the visual response, referred to as a late response, has gained increasing attention in terms of sensory cognition (Del Cul et al., 2007), sensory attention (Roelfsema et al., 1998; Reynolds et al., 2000), iconic memory (Dick, 1974; Benucci et al., 2007), and working memory (Supèr et al., 2001; Harrison and Tong, 2009; Munneke et al., 2010). Because of their relationships with cognitive functions, late sensory responses are expected to be generated through feedback inputs from higherorder cortices (Gilbert and Li, 2013). Indeed, the neuronal activities of higher-order and low-level visual cortices are synchronized during top-down attention (von Stein et al., 2000; Engel et al., 2001; Gregoriou et al., 2009) and stimulation of the frontal cortex enhances the activity of the low-level visual region in monkeys (Moore and Armstrong, 2003). Furthermore, selective stimulation of the direct feedback projection modulates V1 
activity in mice (Zhang et al., 2014). However, this feedback modulation only accounts for a part of the response and much of the late component exists regardless of the top-down influence, which suggests that the late response is composed of inputs from pathways other than top-down feedback.

In this study, we examined the late response of V1 neurons to a brief short visual stimulus (a light flash). We demonstrated previously that V1 neurons exhibit a long late response, as well as an early response, to a light flash and the late response modulates visual perception (Funayama et al., 2015). Here, we focused on the mechanisms underlying these V1 late responses. Specifically, we investigated how these V1 late responses are generated and organized in the visual nervous system. We initially investigated the neuronal circuit mechanism underlying the late response. We patch-clamped V1 layer 2/3 neurons in vivo and recorded their synaptic inputs in response to a brief light flash stimulus. We demonstrated that both excitatory and inhibitory inputs contribute to the late spike responses and that inhibition exerted more control over spike timing. Using pharmacological and optogenetic manipulations of neuronal activity in vivo, we demonstrated that the cortical late response occurs via thalamocortical inputs and emerges in the dLGN. Notably, no similar late response was identified in the retina. Therefore, the V1 late response is generated via a mechanism distinct from the early response.

\section{Materials and Methods}

Ethical approval. Animal experiments were performed with the approval of the Animal Experiment Ethics Committee at the University of Tokyo (approval number: 26-5) and according to the University of Tokyo's guidelines for the care and use of laboratory animals. For human studies, the experimental protocol was approved by the $\mathrm{Hu}$ man Research Ethics Committee of the University of Tokyo (approval number: 24-3) and the Center for Information and Neural Networks (approval number: 1312260010). All participants provided oral and written informed consent and signed consent forms before each experiment.

Animal preparation for recordings. Postnatal day 35 (P35) to P42 male C57BL/6J mice (Japan SLC) were used in the animal experiments, as described previously in detail (Minamisawa et al., 2011; Ishikawa et al., 2014). The animals were housed in cages under standard laboratory conditions (a $12 \mathrm{~h}$ light/dark cycle and with ad libitum access to food and water). All efforts were made to minimize animal suffering and the number of animals used. For Figures $1, C$ and $D, 5, A-C, 7,8$, and 9 , recordings were obtained from urethane-anesthetized mice, whereas for Figures $1, A$ and $B, 3,4,5 D$, and 6 , recordings were obtained from awake mice. For urethane-anesthetized recordings, the animals were anesthetized with urethane $(1.0-1.5 \mathrm{~g} / \mathrm{kg}$, i.p.). Anesthesia was confirmed by the lack of the paw-withdrawal, whisker-movement, and eye-blink reflexes. The head skin was then removed and the animal was implanted with a metal headholding plate. A craniotomy $\left(1 \times 1 \mathrm{~mm}^{2}\right)$ was performed over V1 (centered at $3.5 \mathrm{~mm}$ posterior to bregma and $2.0 \mathrm{~mm}$ ventrolateral to the sagittal suture) or over the dLGN (centered at $1.70 \mathrm{~mm}$ posterior to bregma and $3.5 \mathrm{~mm}$ ventrolateral to the sagittal suture) and the dura was removed surgically. For awake recordings, the surgery and head-hold training were conducted with the same protocol as used in our previous study (Funayama et al., 2015). Briefly, animals were anesthetized with ketamine (50 mg/kg, i.p.) and xylazine (10 mg/kg, i.p.) before the headholding plate surgery and before the craniotomy. Then, after a few days of recovery, animals were trained every day until they could remain immobile under head fixation for $>2 \mathrm{~h}$. For the dLGN recording, regions of the primary somatosensory cortex and the hippocampus were carefully removed by aspiration and the top surface of the dLGN was exposed. The exposed surface was covered with 1.7-2.0\% agar at a thickness of $0.5 \mathrm{~mm}$. Throughout the experiments, a heating pad was used to maintain a rectal temperature of $37^{\circ} \mathrm{C}$ and $0.2 \%$ lidocaine was applied to the surgical region for analgesia.

Visual stimulation. Visual stimuli were generated in custom-written MATLAB routines (The MathWorks) with Psychtoolbox (Brainard, 1997) extensions. For the mouse experiments, a 17-inch TN-LCD monitor (refresh rate $=60 \mathrm{~Hz}$ ) was placed $30 \mathrm{~cm}$ away from the right cornea so that it covered $38.8^{\circ}$ horizontally and $29.6^{\circ}$ vertically of the mouse visual field. For the flash stimulus, a white screen (contrast: 100\%) was presented and its duration was set to $50 \mathrm{~ms}$. The flash stimuli were presented 20-50 times at intervals of $8-10 \mathrm{~s}$ and a gray screen was presented during the interval period. For the human experiments, a visual stimulus was projected from a gamma-corrected LCD projector (Ban and Yamamoto, 2013) to the translucent screen and the participants viewed the screen through a front-surfaced mirror. The viewing distance was 46 $\mathrm{cm}$ and the visual angle of the screen was $51.9 \times 30.6^{\circ}$. The background color of the display was set to black $\left(0.37 \mathrm{~cd} / \mathrm{m}^{2}\right)$. A fixation cross was presented continuously in the center of the screen and the participants were asked to fix their eye position on the cross throughout the task. The start of a trial was indicated by a color change of the fixation cross from red to white $\left(20.0 \mathrm{~cd} / \mathrm{m}^{2}\right)$. After $2000 \mathrm{~ms}$, the whole screen was changed to white $\left(169 \mathrm{~cd} / \mathrm{m}^{2}\right)$ for $50 \mathrm{~ms}$ and subsequently returned to the black screen with the fixation cross. At $4000 \mathrm{~ms}$ after the flash, the color of the fixation cross changed to green, indicating the end of the trial. The participants were asked not to blink during the trial. The participants initiated the trial at their own pace by pressing a key with their right index finger, with a minimum intertrial interval of $5 \mathrm{~s}$. One scan block consisted of 30 trials and the participants performed five (six participants) or six (two participants) blocks during the measurement.

Electrophysiology. The signal was amplified using a MultiClamp 700B, analyzed using pCLAMP10.1 (Molecular Devices), and digitized at 20 $\mathrm{kHz}$. The data were reduced to $2 \mathrm{kHz}$ and analyzed offline using customwritten MATLAB routines. Patch-clamp recordings and local field potential (LFP) recordings were obtained at depths of $150-350 \mu \mathrm{m}$ from the V1 surface, which corresponds to neocortical layer $2 / 3$, or at $50-200$ $\mu \mathrm{m}$ from the dLGN surface using borosilicate glass electrodes (3.5-6.5 $\mathrm{M} \Omega$ ) that were pulled with a P-97 puller (Sutter Instruments). The electrode tips were lowered perpendicularly into V1 with a DMX-11 electric manipulator (Narishige). For the cell-attached recordings, the pipettes were filled with artificial CSF (aCSF). For the whole-cell current-clamp recordings, the intrapipette solution consisted of the following (in $\mathrm{mm}$ ): $130 \mathrm{~K}$-gluconate, $10 \mathrm{KCl}, 10 \mathrm{HEPES}, 10 \mathrm{Na}_{2}$-phosphocreatine, $4 \mathrm{Mg}$ ATP, $0.3 \mathrm{Na}_{2}$ GTP, 0.05 Alexa Fluor 594 hydrazide, and $0.2 \%$ biocytin, adjusted to $\mathrm{pH}$ 7.3. For the voltage-clamp recordings, the intrapipette solution consisted of the following (in mM): $130 \mathrm{CsMeSO}_{4}, 4$ tetraethylammonium- $\mathrm{Cl}, 10$ HEPES, $10 \mathrm{Na}_{2}$-phosphocreatine, 0.5 EGTA, 4 MgATP, $0.3 \mathrm{Na}_{2}$ GTP, 2 QX-314, and 0.05 Alexa Fluor 594. For the retinal multiunit recordings, the intrapipette solution consisted of the following (in mM): $135 \mathrm{NaCl}, 4 \mathrm{KCl}, 1 \mathrm{MgCl}_{2}, 1.8 \mathrm{CaCl}_{2}$, and 5 HEPES. Experiments in which the series resistance exceeded $60 \mathrm{M} \Omega$ or changed by $>15 \%$ during the recording session were discarded. For each neuron, the spike responses to a brief inward current were examined and regular-spiking neurons were selected as putative pyramidal cells for the subsequent recordings. The recorded neurons were confirmed by post hoc Alexa Fluor 594 imaging and only pyramidal cells were analyzed. LFPs and multiunits were recorded using borosilicate glass pipettes (1-2 $\mathrm{M} \Omega$ ) filled with aCSF. The traces were band-pass filtered between 1 and $250 \mathrm{~Hz}$ and high-pass filtered at $250 \mathrm{~Hz}$ for the LFP and multiunit recordings, respectively.

Dynamic-clamp recording. Current-clamped neurons were stimulated using the dynamic-clamp conductance injection technique (Takahashi et al., 2010). The command current $I(t)$ was calculated online as $G_{\mathrm{e}}(t) \times$ $\left(V(t)-E_{\mathrm{e} \_ \text {rev }}\right)+G_{\mathrm{i}}(t) \times\left(V(t)-E_{\mathrm{i} \_ \text {rev }}\right)$, where $G_{\mathrm{e}}(t)$ and $G_{\mathrm{i}}(t)$ comprised time-varying conductances obtained from voltage-clamp recording, $V(t)$ comprised the membrane potential at time $t$; and the reversal potentials $E_{\mathrm{e} \_ \text {rev }}$ and $E_{\mathrm{i} \_ \text {rev }}$ were $0 \mathrm{mV}$ for excitation and $-90 \mathrm{mV}$ for inhibition, respectively. $I(t)$ was delivered into patch-clamped neurons at $20 \mathrm{kHz}$ using a PCI-6024E data acquisition board (National Instruments) in a real-time Linux environment. During conductance injection, the gain was controlled to induce spikes from patch-clamped neurons. 
Wavelet transform of LFP responses. We measured the time-varying oscillatory power of the LFP responses using a complex Morlet wavelet (center frequency of $1.5 \mathrm{~Hz}$, bandwidth parameter of 1) defined as follows:

$$
\begin{gathered}
\tilde{\mathrm{x}}(\mathrm{t})=\int_{-\infty}^{+\infty} x(t) \varphi_{a, b}(t) \mathrm{dt} \text { (Continuous wavelet transform) } \\
\varphi_{a, b}(t)=\frac{1}{\sqrt{a}} \varphi\left(\frac{t-b}{a}\right)
\end{gathered}
$$

The mother wavelet is defined as follows:

$$
\varphi(\mathrm{x})=\sqrt{\pi f_{b}} e^{2 i \pi f_{c^{-x}}} e^{\frac{-x^{2}}{f b}} \text { (Complex Morlet wavelet) }
$$

Where $a$ is the scale factor, $b$ is the shift ( $1 /$ sample rate), $f_{\mathrm{c}}$ is the center frequency, and $f_{\mathrm{b}}$ is the bandwidth parameter. The scale factor $(a)$ was set to frequencies between 1 and $60 \mathrm{~Hz}$ with intervals of $1 \mathrm{~Hz}$.

Virus injection and optogenetic stimulation. For Figures 7 and 8, $0.5 \mu \mathrm{l}$ of AAV2-EF1 $\alpha$-DIO-hChR2(H134R)-EYFP was injected unilaterally into the thalamic reticular nucleus of vesicular GABA transporter (VGAT)-Cre mice. The VGAT-Cre mice were obtained from The Jackson Laboratory (stock number: 016962). AAV2-EF1 $\alpha$-DIO-hChR2(H134R)-EYFP was obtained from the University of North Carolina vector core. The mice were anesthetized with pentobarbital $(0.8 \mathrm{mg} / \mathrm{kg})$ and xylazine $(0.8 \mathrm{mg} / \mathrm{kg})$. The head skin was then removed and a small craniotomy was performed over the thalamic reticular nucleus $1.5 \mathrm{~mm}$ posterior to the bregma and $2.1 \mathrm{~mm}$ ventrolateral to the sagittal suture. The virus was pressure injected at a depth of $3.5 \mathrm{~mm}$ at the speed of $250 \mathrm{~nL} / \mathrm{min}$ (Muromachi). The injection pipette was removed 5 min after the injection ended. Recordings were obtained $4-5$ weeks after the virus injection. An optic fiber attached to a blue laser (473 nm, COME2LB473/100s; Lucir) was illuminated at the target brain region with a power of $10-15 \mathrm{~mW}$. continuously

Human magnetoencephalography (MEG). Eight healthy adults ( 7 males and 1 female, $24.0 \pm 1.4$ years of age) with normal or corrected-tonormal vision participated in the experiment. The participants were placed in a supine position in the scanner. The MEG signal was recorded from 306 channels (204 planar gradiometers, 102 magnetometers, Elekta Neuromag TRIUX) at a sampling rate of $1000 \mathrm{~Hz}$ and was band-pass filtered between 0.03 and $330 \mathrm{~Hz}$. Eye movements and blinks were recorded simultaneously by the electrodes placed on the right eyelid. The raw MEG data were preprocessed using Maxfilter software (Elekta). First, a $45 \mathrm{~Hz}$ low-pass filter was applied. Noise reduction was subsequently performed with spatiotemporal filters (Taulu et al., 2004; Taulu and Simola, 2006). Default parameters were used for this process (harmonic expansion origin in the head frame $=\left[\begin{array}{lll}0 & 0 & 40\end{array}\right] \mathrm{mm}$; expansion limit for internal multipole base $=8$; expansion limit for external multipole base $=3$; bad channels automatically excluded from harmonic expansions $=7 \mathrm{SD}$ above average; temporal correlation limit $=0.98$; and buffer length $=10 \mathrm{~s}$ ). The resulting filtered data were subsequently analyzed using the Fieldtrip toolbox (http://www.ru.nl/neuroimaging/fieldtrip). A single trial dataset was extracted during the period $600 \mathrm{~ms}$ before the flash and $3000 \mathrm{~ms}$ after the flash. The trials in which the eye blink occurred during this period were excluded by visual inspection. Electrocardiographic signals were removed using an independent component analysis. For each trial, we removed the baseline ( -500 to $0 \mathrm{~ms}$ ) mean from the data of each channel. The planar gradiometers are considered to reflect the neural activity from immediately below the sensors. Therefore, the posterior 120 gradiometers that covered the whole occipital cortex were used for the analysis. First, we combined the signals from the two gradiometers, which measured the two different orientations of the magnetic field at the sensor location. Second, for each individual participant, we identified the most active sensor within the posterior sensors at the same time as a flash-evoked early response occurred in the mouse V1. This sensor likely reflects the visual evoked field originating from the early visual cortex (e.g., V1). We reported previously that the initial peak latency of the flash-evoked electroencephalographic response was, on average, $47 \mathrm{~ms}$ (Funayama et al., 2015). Therefore, we calculated the strength of the evoked response by averaging the period of $40-65 \mathrm{~ms}$ after the flash. Finally, we examined the activity of these sensors for the entire duration of the trial, between -500 and 3000 ms. Note that our purpose was to determine whether a late response may be observed reliably for the visual area sensors that exhibit a flash-evoked early response. Therefore, our criterion for the channel selection was independent of our aim that considered the late response. To evaluate the origin of MEG signals during the late period, we applied the MEG source localization analysis using the software package MNE (Gramfort et al., 2014) and in-house MATLAB subroutines. Both gradiometer and magnetometer signals were used and their response units were adjusted using a subroutine equipped in MNE. The source space at the first-level analysis (individual subject-based analysis) was based on the left and right cortical surfaces defined by the gray and white matter boundaries, which were segmented from high-resolution T1-weighted anatomical images $(1 \times$ $1 \times 1 \mathrm{~mm}^{3}$ voxels, 208 slices) using the software package FreeSurfer (Dale and Sereno, 1993; Dale et al., 1999). The T1-weighted anatomical images were obtained separately for each participant with a Siemens 3T Trio MR scanner using a 32-channel phased-array whole-head coil, equipped at the Center for Information and Neural Networks (NICT, Japan). For the second-level (group) analysis, individual cortical surfaces were registered to the spherical coordinate system defined in FreeSurfer. The spherical surfaces were then morphed and averaged across eight participants so that individual cortical folding geometries matched across subjects (Fischl et al., 1999). Finally, the MEG source estimates for the individual surfaces were morphed and transformed into an averaged cortical surface space using the same deformation parameters. The averaged MEG source estimates were evaluated and visualized using dynamic statistical parametric map (dSPM) F statistics (Dale et al., 2000).

\section{Results}

Flash-induced late response in mouse V1 layer 2/3

In our previous study (Funayama et al., 2015), we visually stimulated awake mice with a brief presentation of a sinusoidal grating as a flash stimulus. Here, we used a simpler stimulus, a whitescreen plain flash, to unmask the basic principles for the functional organization of flash-evoked cortical late responses. To confirm that a white-screen flash induces a similar late response in V1, we first conducted whole-cell current-clamp recordings from V1 layer 2/3 using a potassium-based intracellular solution (Fig. $1 A, B$ ). Consistent with our previous findings, the white-screen flash induced biphasic voltage responses $\left(V_{\mathrm{m}}\right)$ that were composed of a fast, transient depolarization (early response) and thena late, prolonged depolarization (late response). The biphasic responses were identified in all 30 neurons tested in 26 mice. On average, the early depolarization had a peak amplitude of $1.3 \pm 0.5 \mathrm{mV}$ (mean \pm SEM of 30 neurons) and a peak latency of $70.0 \pm 7.3 \mathrm{~ms}$, whereas the slow depolarization persisted from $\sim 0.4$ to $2.0 \mathrm{~s}$ after the stimulation and had a peak amplitude of $9.3 \pm 1.1 \mathrm{mV}$. The variety in the peak timing of the late responses among cells resulted in seemingly lower late $V_{\mathrm{m}}$ peak amplitudes in the average trace shown in Figure $1 B$. These depolarizations were occasionally accompanied by action potentials. Specifically, 2 of 30 neurons fired spikes during the early depolarization period (0-0.2 s after the flash), and the mean firing rate of these two early spiking cells was $3.8 \mathrm{~Hz}$. During the late depolarization period $(0.4-2.0 \mathrm{~s}), 15$ of 30 neurons exhibited firing and the mean firing rate of the late spiking cells was $0.59 \pm$ $0.15 \mathrm{~Hz}$. Note that the spontaneous firing rate during the preflash baseline period was $0.08 \pm 0.12 \mathrm{~Hz}$.

To determine whether flash-induced biphasic responses depend on the brain state of the mouse, we conducted whole-cell current-clamp recording and LFP recording (Fig. $1 C-E$ ) simultaneously under anesthesia. We observed similar biphasic $V_{\mathrm{m}}$ responses even in anesthetized mice. Consistent with previous 
A Awake
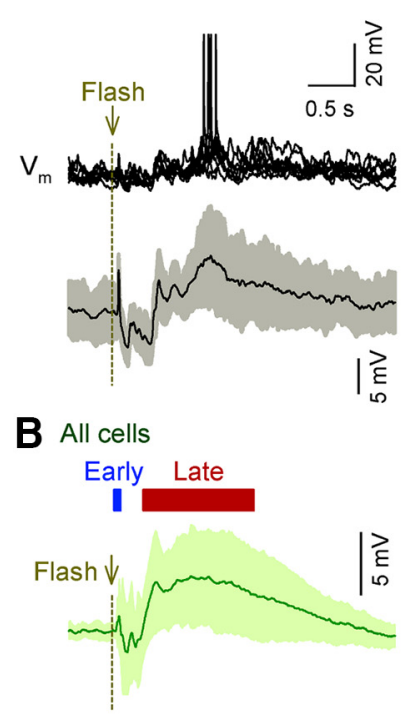

C Anesthetized

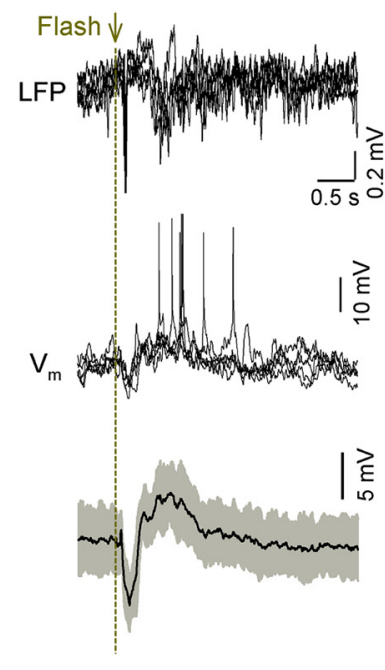

D LFP Power $\quad\left(\mathrm{mV}^{2} / \mathrm{Hz}\right)$
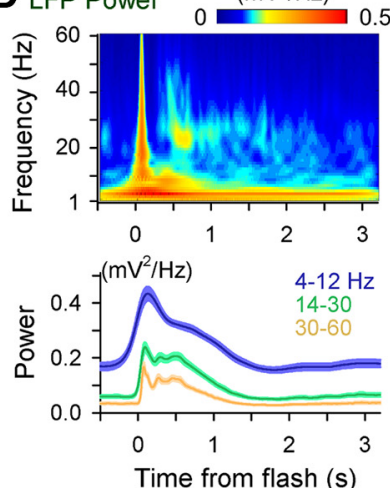

E Multi-unit

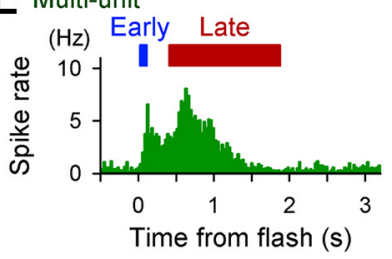

Figure 1. A flash of light induces a delayed response in layer $2 / 3$ neurons of the mouse primary visual cortex. Electrophysiological recordings were made in both awake $(\boldsymbol{A}, \boldsymbol{B})$ and urethaneanesthetized $(\boldsymbol{C}-\boldsymbol{E})$ mice. $\boldsymbol{A}$, Whole-cell current-clamp recordings were acquired from V1 layer 2/3 neurons in awake, head-restricted mice in which the contralateral eyes were presented with full-field white flashes at pseudorandom intervals of $8-10 \mathrm{~s}$ for 50 trials. Top, Five representative trials of $V_{\mathrm{m}}$ responses in a pyramidal neuron. Bottom, Mean subthreshold $V_{\mathrm{m}}$ responses across all 50 trials in the same neuron. The gray area represents the SD. B, Mean \pm SD subthreshold $V_{m}$ responses of all 30 neurons recorded from 26 mice. $C$, Raw recording traces of LFPs (top) and $V_{m}$ responses of a single pyramidal cell (middle) were simultaneously acquired from layer $2 / 3$ of mouse $V 1.0$ f 50 trials of flash stimuli presented to the contralateral eye, five randomly selected trials are shown. Bottom, Mean $\pm S D$ subthreshold $V_{\mathrm{m}}$ responses of the example neuron. $D$, Top, Mean powers of LFPs were computed using the wavelet transform. Bottom, Mean \pm SEM of the LFP powers for all 28 LFP recordings from 28 mice. $\boldsymbol{E}$, Histogram of spike responses for all eight multiunit recordings from eight mice.
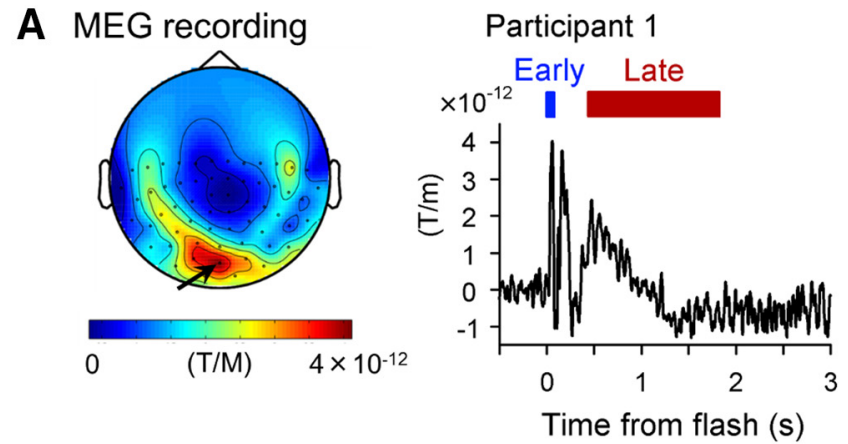

\section{C dSPM analysis}

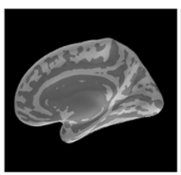

0

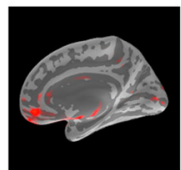

350

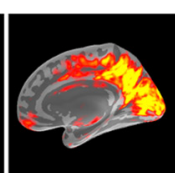

100

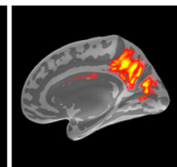

450

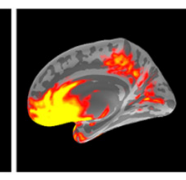

250

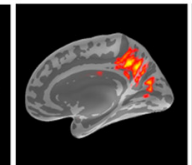

550
B All participants

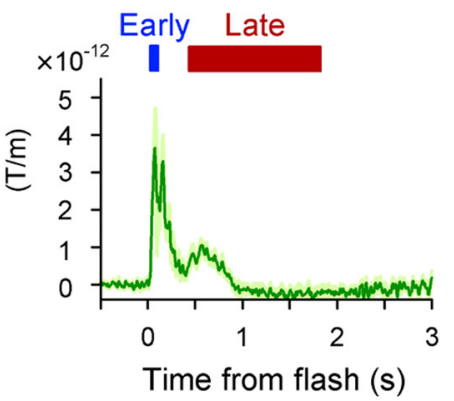

Time from flash (s)

Time from flash

Figure 2. A flash of light induces a late response in the human occipital cortex. A, Left, Topographical plot of the MEG response in the occipital channels. Representative data from a single participant are shown. Color indicates the intensity of the signal at $40-65 \mathrm{~ms}$ after the flash. Right, Time course of the MEG signal recorded in the occipital channel shown by the arrow. Data represent the means of 120 trials. $\boldsymbol{B}$, Average \pm SD time course data of the most active occipital channel across all eight participants. Periods indicated in red represent the time point at which the signal increased significantly compared with the period before the flash ( $p<0.05$, FDR corrected). C, ASPM analysis using the average MEG signal recorded from eight participants. 

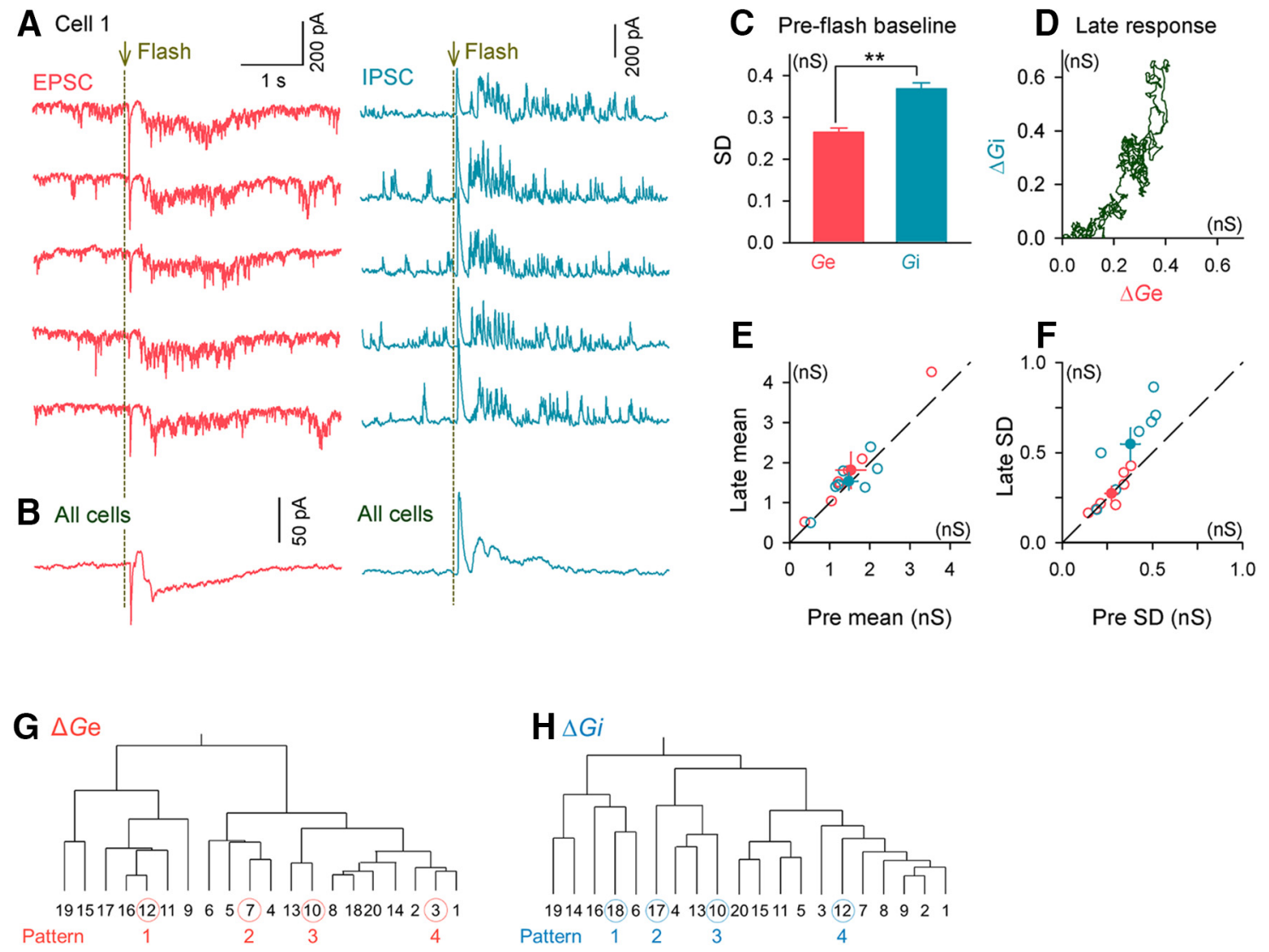

Figure 3. A flash of light modulates excitatory and inhibitory conductances differentially. $A$, Whole-cell voltage-clamp recordings were acquired from layer $2 / 3$ primary visual cortical neurons while $20-50$ trials of a flash were presented to the contralateral eye. EPSCS and IPSCS were recorded at clamped voltages of -74 and $0 \mathrm{mV}$, respectively. Five randomly selected traces of EPSCs and IPSCs from a representative neuron are shown. $\boldsymbol{B}$, Mean EPSC and IPSC traces of seven cells from six mice. $\boldsymbol{C}$, Mean \pm SD of the fluctuations (SDs) in $G_{\mathrm{e}}$ and $G_{\mathrm{i}}$ during individual trials during the preflash baseline period. Error bars indicate the SEMs of seven cells from six mice. ${ }^{* *} p=9.79 \times 10^{-13}, t_{(149)}=7.80$, Student's test, $n=150$ trials. $D$, Time course of the relationship between the mean $G_{\mathrm{e}}$ and $G_{\mathrm{i}}$ during the late responses. Data are the same as in $\boldsymbol{B} . \boldsymbol{E}, \boldsymbol{F}$, Comparisons of flash-induced changes in the means $(\boldsymbol{E})$ and $S D s(\boldsymbol{F})$ of the $G_{\mathrm{e}}$ and $G_{\mathrm{i}}$ during the late responses. $\Delta S D$ of $G_{\mathrm{e}}$ versus $G_{i}, p=9.21 \times 10^{-3}, t_{(6)}=3.78$, Student's $t$ test, $n=7$ cells from 6 mice. $\boldsymbol{G}, \boldsymbol{H}$, In a representative neuron, 20 EPSC $(\boldsymbol{A})$ and IPSC $(\boldsymbol{B})$ traces $(2.5 \mathrm{~s}$ in length) were classified using Ward's method. Four traces were selected from each dendrogram and were used to generate synaptic conductance patterns, $\Delta G_{\mathrm{e}}$ and $\Delta G_{\mathrm{i}}$, in the subsequent dynamic-clamp experiments.

studies, the $V_{\mathrm{m}}$ fluctuations of nearby neurons are reflected in LFPs (Deweese and Zador, 2004; Haider et al., 2006; Poulet and Petersen, 2008). A flash induced a transient early increase and a persistent late increase in the LFP powers at frequencies of 1-60 $\mathrm{Hz}$ (Fig. 1D). Furthermore, multiple units in the LFPs also exhibited biphasic increments in the firing rates (Fig. $1 E$ ). Therefore, a simple white-screen flash induced biphasic responses in a large population of V1 neurons.

We next focused on the trial-to-trial variability of the late responses. Because the LFP powers between 1 and $60 \mathrm{~Hz}$ fluctuated in a similar way (Fig. $1 D$, bottom), we extracted the mean gamma powers $(30-60 \mathrm{~Hz})$ of individual stimulation trials from 28 LFP recording in 28 mice. For each trial, we analyzed the gamma-frequency power during the late responses and compared it with the preflash gamma power. We observed that the late gamma power in a given trial was negatively correlated with the preflash baseline $\left(R^{2}=-0.19 \pm 0.23\right.$, mean \pm SD of 29 mice; $\left.p=1.7 \times 10^{-4}, t_{(28)}=4.34\right)$. Therefore, the late response was modulated by the brain state before the flash stimulus.

Flash-induced late response in the human occipital cortex

We also used MEG to investigate whether a plain flash induces early and late complex responses in humans. In each participant, the location of the MEG sensor that exhibited the highest activity during the period of $40-65 \mathrm{~ms}$ after a light flash was defined as the occipital region of the brain (Fig. $2 A$ ). These sensors most likely reflected the initial evoked field that originated in the early visual cortex. In 8 participants, we tracked the evolution of activity in the sensors over time and identified a significant reactivation of the sensor during the period $0.4-1 \mathrm{~s}$ after the flash (Fig. $2 B)$. We further evaluated the biphasic responses in the occipital region using $\mathrm{dSPM}$ analysis, which estimates the source localization of the response signal (Fig. 2C). This approach revealed that early and late responses were evident in the occipital region. Therefore, the human activity pattern resembles the biphasic responses of the mouse V1. Interestingly, during the onset time of the late responses (such as a time frame of $450 \mathrm{~ms}$ ), brain regions other than the occipital cortex appeared silent and the late responses seemed to be initiated from the visual cortex, at least at the cortical level.

\section{V1 late synaptic inputs}

We subsequently returned to the V1 cortex of awake mice and sought to determine how the V1 late response is generated. We first examined the synaptic inputs underlying the depolarization of the V1 late response. We obtained whole-cell voltage-clamp recordings using a cesium-based internal solution. Individual trial traces and the averaged traces of the EPSC-dominant and IPSC-dominant currents are shown in Figure 3, $A$ and $B$, respectively. In both traces, the early and late responses were evident. 
A

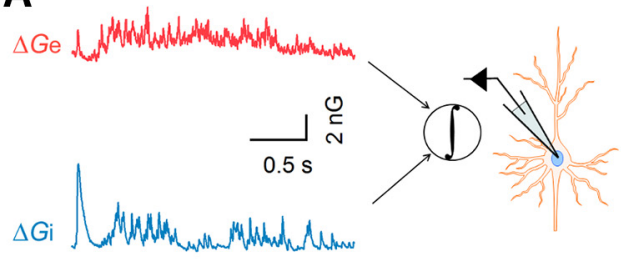

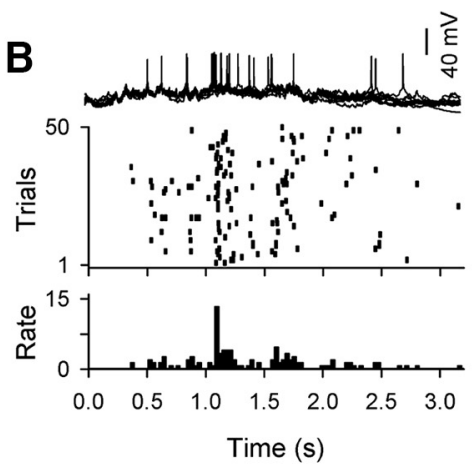

C

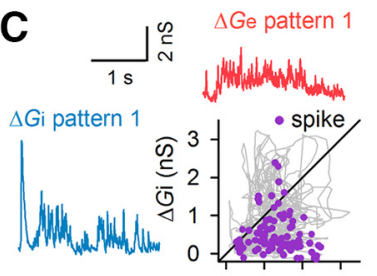

pattern 2

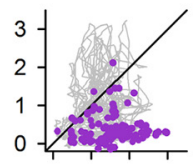

pattern 3

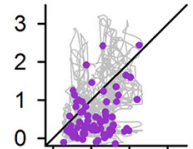

pattern 4
S
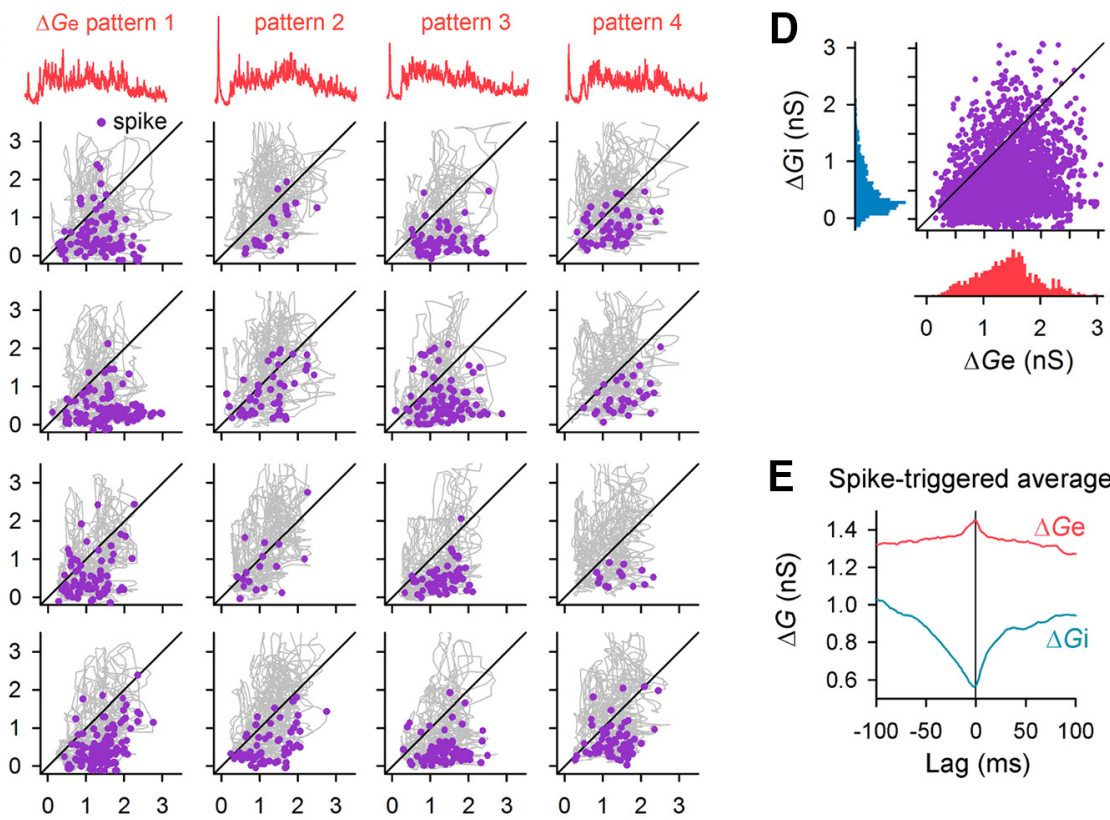

E Spike-triggered average
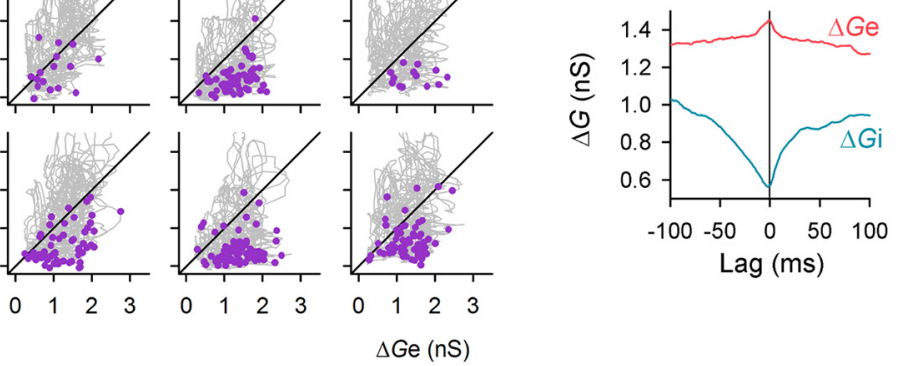

$\operatorname{Lag}(\mathrm{ms})$

Figure 4. Inhibitory inputs determine the timing of late spikes. $A$, Current-clamped neurons were stimulated using the dynamic-clamp technique. Four patterns of each $\Delta G_{\mathrm{e}}$ and $\Delta G_{\mathrm{i}}$ were paired, yielding $16(4 \times 4)$ patterns of mixed conductances. $\boldsymbol{B}$, Each conductance pattern was injected for $20-50$ trials. Top, Five traces from a representative neuron. Bottom, Raster plot of spikes evoked in all 50 trials and the time histogram. $C$, Relationships between the $\Delta G_{e}$ and $\Delta G_{i}$ levels and spikes recorded from a single representative neuron. Only late spikes during the postflash period of $0.4-2.0 s$ were analyzed. Gray lines indicate the trajectories in space of the $\Delta G_{e}$ and $\Delta G_{i}$ as a function of time. Purple dots indicate the timing of spikes on the trajectories. $D$, Summary of data for all six neurons. The left and bottom histograms indicate the distributions of the spike counts. $E$, Spike-triggered average of the $\Delta G_{\mathrm{e}}$ and $\Delta G_{\mathrm{i}}$ for all 4885 spikes.

Therefore, the biphasic responses were associated with a coordinated increase in excitation and inhibition. The averaged EPSC traces exhibited a seemingly outward transient current after the early flash response. This outward current may simply be caused by a reduction in the tonic excitation that was present during prestimulus basal conditions; however, voltage-clamp recordings, especially when conducted in vivo, are vulnerable to the space-clamp problem, which might also underlie the outward current.

We initially analyzed the background synaptic conductances before the presentation of the flash stimulus. Individual traces indicated that during the preflash baseline conditions, the IPSCs often occurred as a form of large, barrage-like synaptic inputs compared with the EPSCs (Fig. 3A). To quantify this difference in the input patterns, we calculated the SD of the membrane potential fluctuations during the preflash period. Consistent with the eye inspection, the $G_{\mathrm{i}}$ had a significantly larger SD than the $G_{\mathrm{e}}$ (Fig. $3 C ;{ }^{* *} p=9.79 \times 10^{-13}, t_{(149)}=7.80, G_{\mathrm{e}}$ vs $G_{\mathrm{i}}$, Student's $t$ test, $n=150$ trials from 7 cells from 7 mice). The amplitudes of the individual IPSC barrages ranged from $\sim 100$ to $300 \mathrm{pA}$ and were larger than the amplitudes of the unitary IPSCs evoked by single GABAergic synapses (Yoshimura and Callaway, 2005; Ren et al., 2007), which suggests that they were produced by synchronized inhibitory inputs from presynaptic interneuron ensembles.

We subsequently analyzed the changes in the $G_{\mathrm{e}}$ and $G_{\mathrm{i}}\left(\Delta G_{\mathrm{e}}\right.$ and $\Delta G_{\mathrm{i}}$, respectively) during the late responses that were identified $0.4-2.0 \mathrm{~s}$ after the flash. The membrane potential may be imperfectly clamped; therefore, we calculated the change in conductance, rather than the absolute conductance values, by subtracting the prestimulus mean value. This calculation was also expected to cancel out the effect of the cesium-based solution on the membrane potential given that cesium ions block ion channels associated with the resting conditions. The time-evolution plot of the mean $\Delta G_{\mathrm{e}}$ and $\Delta G_{\mathrm{i}}$ across all 7 cells indicated that the $\Delta G_{\mathrm{e}}$ was approximately proportional to the $\Delta G_{\mathrm{i}}$ for the entire period of $1.6 \mathrm{~s}$ (Fig. 3D), indicating that the excitatory and inhibitory inputs were co-tuned at a given time point. However, for the individual trials, the pattern of flash-induced conductance changes differed between the $G_{\mathrm{e}}$ and $G_{\mathrm{i}}$ (Fig. $3 A$ ); that is, the $G_{\mathrm{e}}$ increases appeared to be shaped by a tonic increase in the synaptic inputs, whereas the $G_{\mathrm{i}}$ increases appeared to result from an increase in the number of large IPSC barrages. The mean $G_{\mathrm{e}}$ and $G_{\mathrm{i}}$ 

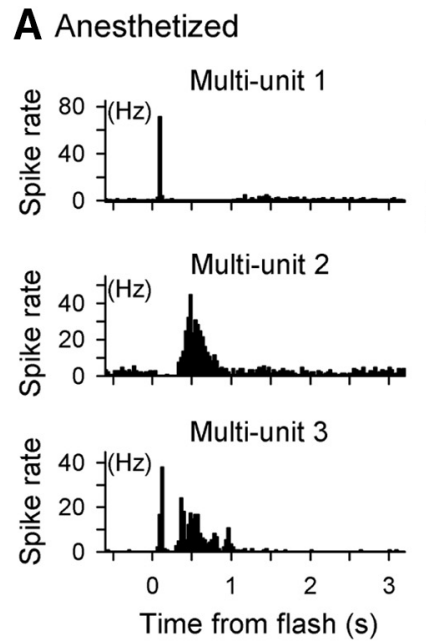

B All recordings

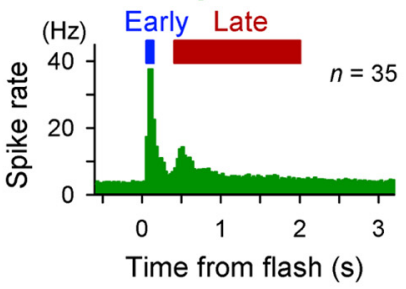

C Awake
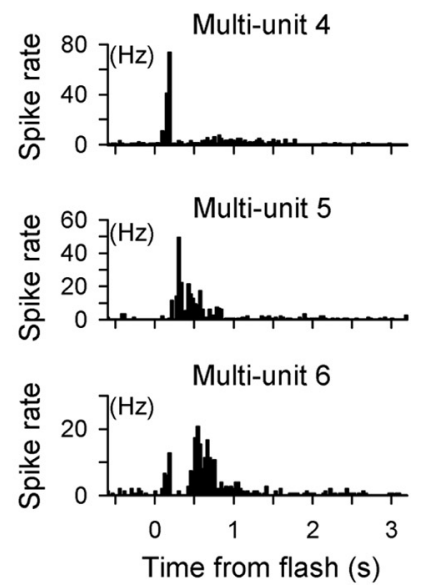

Figure 5. A flash of light evokes biphasic spike responses in the dLGN. The primary somatosensory cortex (S1) and hippocampus were partially removed and the dLGN was exposed to allow routine electrophysiological recordings. A flash was presented to the contralateral eye. Recordings were obtained from urethane-anesthetized $(\boldsymbol{A}, \boldsymbol{B})$ and awake $(\boldsymbol{C})$ mice. $\boldsymbol{A}$, Three representative peristimulus time histograms (PSTHs) of spikes in multiunit recordings from anesthetized mice. $\boldsymbol{B}$, Data from 36 unit recordings from 20 mice were pooled. $\boldsymbol{C}$, Three representative PSTHs of spikes in multiunit recordings from awake mice.
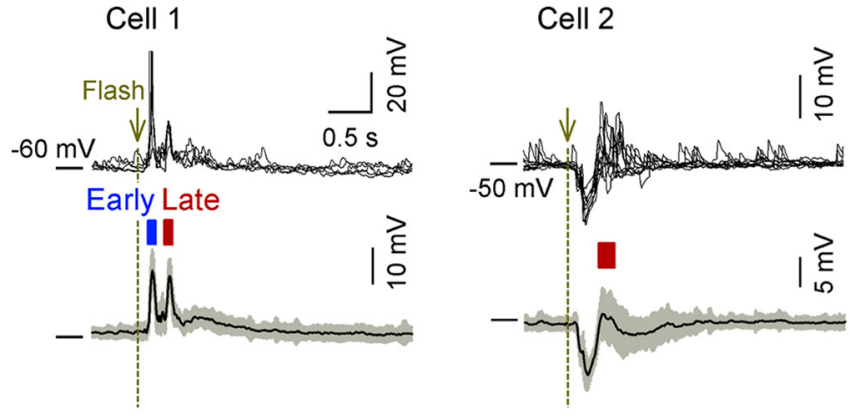

Cell 4

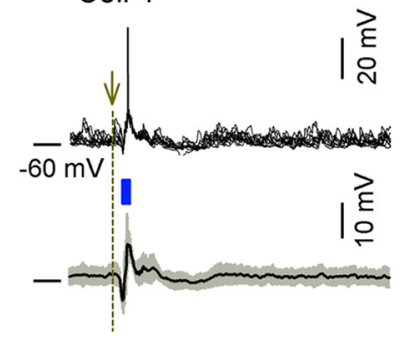

Cell 5

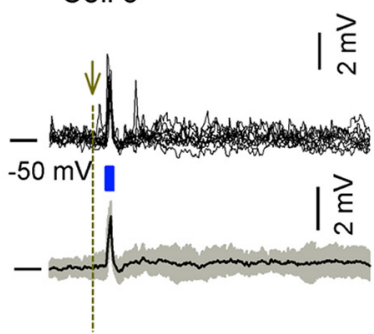

Cell 3

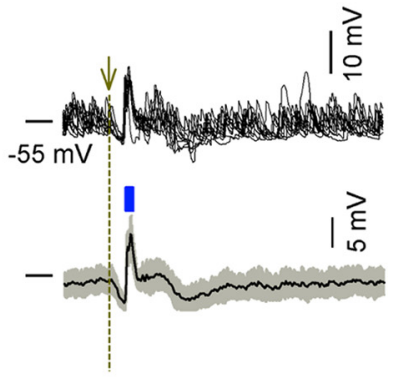

Cell 6

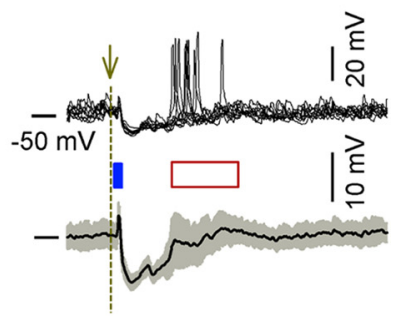

Figure 6. A flash of light evokes various subthreshold responses in dLGN neurons. Whole-cell current-clamp recordings were acquired from six dLGN neurons in awake, head-restricted mice in which the contralateral eyes were presented with full-field white flashes at pseudorandom intervals of $8-10$ s for 50 trials. Representative 10 trials of raw $V_{m}$ responses of six neurons (top) and their mean $\pm S D$ subthreshold $V_{m}$ responses (bottom) are shown. The blue and red boxes above the subthreshold response show the significant early $(0-0.3 \mathrm{~s})$ and late $(0.4-2.0)$ responses, respectively. The red-edged white box shows cell 6 , which exhibited late spike responses even though it did not exhibit significant depolarization at the subthreshold level.

values increased to similar degrees in response to flashes (Fig. 3E), whereas an increase in the SD was identified in the $G_{\mathrm{i}}$, but not in the $G_{\mathrm{e}}$ (Fig. $3 F ; p=9.21 \times 10^{-3}, t_{(6)}=3.78, G_{\mathrm{e}}$ vs $G_{\mathrm{i}}$, Student's $t$ test, $n=7$ cells from 7 mice).

\section{Spike timing during late responses}

In the previous analysis, we demonstrated that, even though the overall balance of excitatory and inhibitory synaptic inputs was maintained during the late response, their input patterns differed for individual trials (Fig. 3A). This finding implied that excitatory and inhibitory inputs may show transient imbalances and thereby determine the timing of late spikes. To characterize the synaptic mechanisms that determine late spike timing, it is important to identify which of the two synaptic inputs exerted more control over the spike timing. We investigated this issue using the dynamic-clamp conductance injection technique. Due to methodological limitations, we were not able to record $G_{\mathrm{e}}$ and $G_{\mathrm{i}}$ simultaneously within a single trial. Therefore, we applied dendrogram clustering to flash-evoked $G_{\mathrm{e}}$ and $G_{\mathrm{i}}$ patterns to classify them into several subsets (Fig. $3 G, H$ ). Then, we selected four representative patterns of $G_{\mathrm{e}}$ and $G_{\mathrm{i}}$ (poststimulus $2.5 \mathrm{~s}$ in length) from these subsets so that we could maximize the combinatorial repertoires of the $G_{\mathrm{e}}$ and $G_{\mathrm{i}}$ patterns. We subtracted the preflash baseline from individual $G_{\mathrm{e}}$ and $G_{\mathrm{i}}$ patterns $\left(\Delta G_{\mathrm{e}}\right.$ and $\Delta G_{\mathrm{i}}$, re- 
A

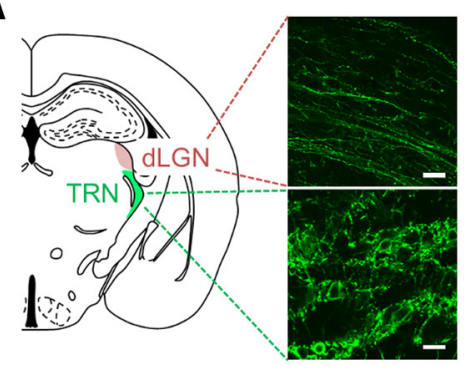

B

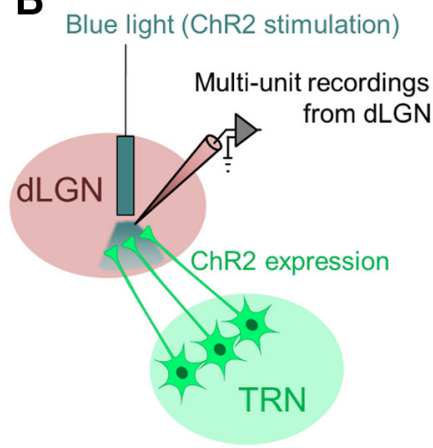

C Multi-unit recordings from dLGN
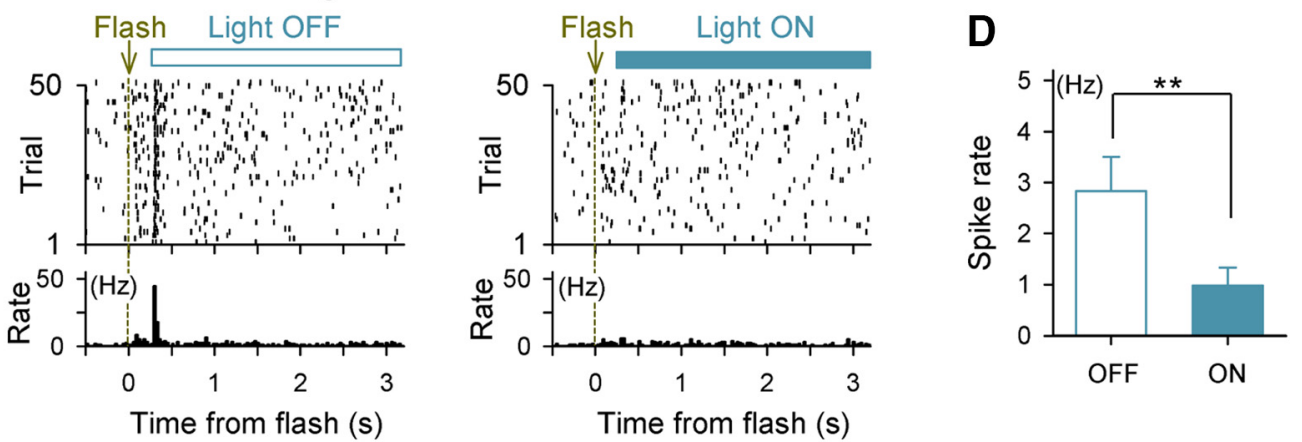

Figure 7. Selective activation of the thalamic reticular nucleus inhibits spikes of dLGN neurons during the time window of V1 late responses. A, AAV2-EF1 $\alpha$-DI0-hChR2(H134R)-EYFP was injected into the thalamic reticular nucleus (TRN) of VGAT-Cre transgenic mice to express ChR2 selectively in GABAergic neurons in the TRN. Confocal images of the ChR2-expressing axons (top) and cell bodies (bottom) of TRN neurons are shown in the insets. Scale bar, $20 \mu \mathrm{m}$. B, Schematic of the experimental protocol. Multiunit recordings were acquired from the dLGN while a blue light was applied to the dLGN through an optic fiber implant to activate the ChR2-expressing axons of TRN neurons, resulting in the specific inhibition of LGN neurons. C, Spike raster plot of dLGN multiunit recordings (top) and its peristimulus time histogram (bottom). Fifty trials of flash stimuli were presented to the contralateral eye without (left, light OFF) or with (right, light $0 \mathrm{~N}$ ) blue light stimulation. For the light $0 \mathrm{~N}$ trials, a blue light was presented $0.2-3.2$ s after a flash stimulus to inhibit the $\mathrm{dLGN}$ specifically in the time window of the V1 late response without affecting the early response. $D$, Mean \pm SEM multiunit spike rates of light $0 \mathrm{~N}$ and light $\mathrm{OFF}$ trials, respectively. ${ }^{*} p=0.0073, t_{(4)}=5.02, n=5$ recordings from 2 mice, paired $t$ test.

spectively) and arbitrarily combined a single $\Delta G_{\mathrm{e}}$ trace and a single $\Delta G_{\mathrm{i}}$ trace for each experimental session to generate artificial whole-cell conductance pattern that may mimic the late responses. Using dynamic clamp recording (Takahashi et al., 2010), we injected the combinations of single $\Delta G_{\mathrm{e}}$ and $\Delta G_{\mathrm{i}}$ traces into current-clamped neurons during spontaneous conditions without flash stimuli (Fig. 4A) and recorded the spike responses of the neurons (Fig. $4 B$ ). The neurons spiked at times when the $\Delta G_{\mathrm{i}}$ became small (Fig. $4 C, D$ ). The spike-triggered averages of the injected conductances indicated that the $\Delta G_{\mathrm{i}}$ exhibited a larger change (time locked to a spike) than the $\Delta G_{\mathrm{e}}$ (Fig. $4 E$ ). These data suggested that, although both excitatory and inhibitory inputs contributed to spikes, they were involved in different ways; tonic increases in the $\Delta G_{\mathrm{e}}$ depolarized the membrane potential, whereas intermittent drops in the $\Delta G_{\text {i }}$ provided opportunities to evoke spikes. Note that the large variability of inhibitory inputs (i.e., an increase in $G_{\mathrm{i}}$ barrage events; Fig. $3 F$ ) may conversely generate the intermittent decreases in $G_{\mathrm{i}}$. These findings indicate that inhibitory inputs have a greater effect on spike timing than do excitatory inputs (Wehr and Zador, 2003; Higley and Contreras, 2006).

\section{Source of the V1 late response}

Because flash-induced late responses were generated by organized synaptic inputs, they comprised a network-dependent phenomenon. We subsequently searched for the brain region that initiated the late response. Because late responses were observed in both the awake and anesthetized states, we conducted the following experiments mainly using anesthetized animals. We ex- amined two major candidates:top-down feedback pathways from higher-order cortices (Zhang et al., 2014; Manita et al., 2015) and bottom-up feedforward pathways from the retina or thalamus.

We first investigated whether V1 late responses depended on the activity of higher-order cortices. Visual information flows from $\mathrm{V} 1$ to the anterior cingulate cortex (ACC), as well as to the secondary visual cortex (V2) (Mohajerani et al., 2013; Zhang et al., 2014). These higher cortical regions also project back to V1 and modulate V1 neuronal activity (Zhang et al., 2014). We evaluated whether the inhibition of ACC activity abolishes the V1 late response. We applied $10 \mu \mathrm{M}$ tetrodotoxin, an inhibitor of voltage-sensitive sodium channels, to the pial surface of the ACC of anesthetized mice for $20 \mathrm{~min}$. This condition was sufficient to inhibit the neuronal activity of this region (Funayama et al., 2015). We subsequently recorded flash-evoked LFP responses in V1. The application of tetrodotoxin slightly reduced the flashinduced late LFP powers; however, its effect was not statistically significant and the late response was largely intact (data not shown, $p>0.05$; paired $t$ test, $n=6$ mice). Therefore, we concluded that ACC is not likely the major synaptic driver of the late response, at least under anesthesia.

We subsequently examined the possibility that the late response uses the same feedforward path as the early response. Therefore, we hypothesized that the $\mathrm{V} 1$ late response is generated upstream of the visual pathway. We first conducted multiunit recordings from the dLGN from anesthetized mice. To permit reliable access to the $\mathrm{dLGN}$, a part of the primary somatosensory cortex and the hippocampus above the dLGN were removed. After this surgical treatment, we conducted routine recordings 


\section{A LFP recordings from $\mathrm{V} 1$}
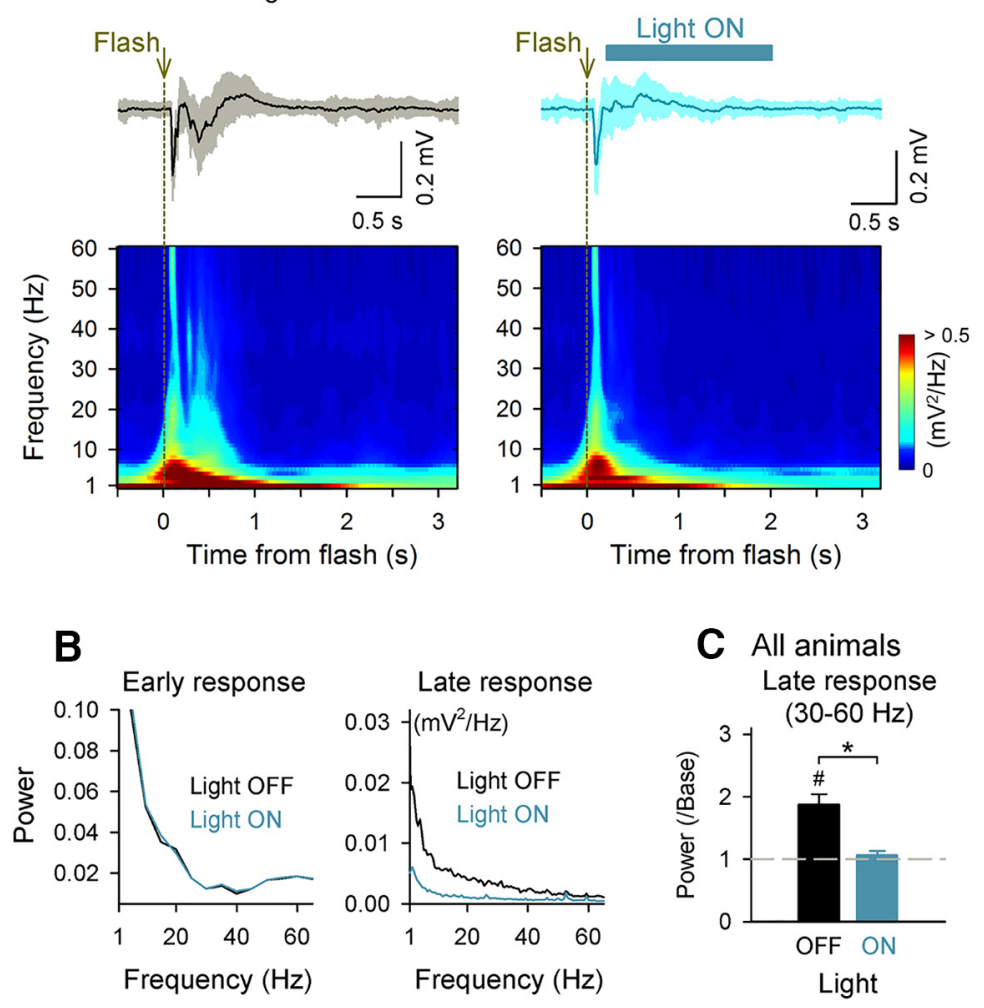

Figure 8. Selective inhibition of dLGN suppresses the V1 late response. $A, A$ blue light was applied to the dLGN to activate ChR2-expressing axons of TRN neurons. Flash-induced LFP responses were recorded from V1 layer 2/3 without (left) and with a blue light (right, light ON). In the light ON trials, a blue light was presented 0.2-2.2 s after a flash. Top, Stimulus-evoked LFP traces are shown as the mean \pm SD. Bottom, Mean powers of flash-evoked LFPs were computed using the wavelet transform. $\boldsymbol{B}$, Mean powers of LFPs in $\boldsymbol{A}$ were analyzed during the time windows of the early response (left, $0-0.3 \mathrm{~s}$ ) and the late response (right, $0.4-2.0 \mathrm{~s})$ using fast Fourier transform. C, LFP powers in the gamma-frequency range $(30-60 \mathrm{~Hz})$ were compared between the light OFF trials (black) and light $\mathrm{ON}$ trials (blue) in all seven animals tested (50 trials each). ${ }^{*} p=0.011, t_{(6)}=3.57, \# p=0.022$, $t_{(6)}=3.03$, paired $t$ test.

to monitor the dynamics of dLGN neurons (Fig. $5 A, B$ ). Similar to the case in V1 neurons, a flash stimulus induced three types of response patterns. Of 36 recordings, six recordings (16.7\%) showed early spiking only, one recording $(5.6 \%)$ showed late spiking only, and 28 recordings (77.8\%) showed both early and late spiking (Fig. $6 C, D$ ). This response variability may reflect the sum of multiunit spikes from a few neurons in each recording; for instance, a recording that showed both early and late spikes may contain both an early-spiking neuron and a late-spiking neuron or it may contain a neuron that showed both early and late spikes.

Thalamic activity pattern is known to be influenced substantially by brain states such as anesthesia, sleep, and arousal (Sherman, 2001; Weyand et al., 2001). Although we observed late visual responses of $\mathrm{V} 1$ neurons in both awake and anesthetized states, it is possible that dLGN neurons exhibit late responses only in anesthetized animals. Therefore, we recorded multiunit recordings from the dLGN in awake mice. Under these conditions, we observed biphasic dLGN activity similar to that under anesthesia (Fig. 5C).

We next examined the $V_{\mathrm{m}}$ responses individual dLGN neurons of awake mice using whole-cell current-clamp recordings. We successfully performed current-clamping on six LGN neurons and the traces of all six cells are presented in Figure 6 . The $V_{\mathrm{m}}$ responses of dLGN neurons varied between cells. Some neurons showed either early or late $V_{\mathrm{m}}$ responses (cells 2, 3, 4, and 5), whereas other neurons showed both responses (cells 1 and 6). The $V_{\mathrm{m}}$ waveforms were also variable among cells. Cell 1 reliably showed a sharp late depolarization (cell 1), whereas other neurons showed a large hyperpolarization before late depolarization (cells 2 and 6). Because most V1 neurons exhibited both early and late $V_{\mathrm{m}}$ depolarization, the dLGN responses were different from those of $\mathrm{V} 1$ neurons; nonetheless, we confirmed that late-responding neurons were present in the dLGN of awake mice.

Although a flash evoked a late response in the dLGN, it remains possible that $\mathrm{V} 1$ received late synaptic inputs via other afferents (Felleman and Van Essen, 1991; Zingg et al., 2014). To confirm the necessity of dLGN late activity for V1 late responses, we investigated whether the timed inhibition of the dLGN activity during the time window of the V1 late response suppresses the $\mathrm{V} 1$ late response. If the late response arises through the same pathway as the early response, then the $\mathrm{V} 1$ late response would disappear when the dLGN is silenced specifically during the late response. To address this question, we used an optogenetic technique described previously (Reinhold et al., 2015). To silence the relay neurons of the dLGN, we expressed channelrhodopsin-2 (ChR2) in GABAergic neurons of the thalamic reticular nucleus (Halassa et al., 2011), a region that sends a direct GABAergic projection to the dLGN (Guillery and Harting, 2003; Saalmann and Kastner, 2009). We conditionally expressed ChR2 by injecting a Credependent adeno-associated virus encoding ChR2 into the thalamic reticular nucleus of a VGAT-Cre transgenic mouse (Fig. 7A,B; Vong et al., 2011). The illumination of ChR2expressing GABAergic axons in the dLGN with a blue light $0.2-3.2 \mathrm{~s}$ after the flash-evoked early response suppressed the late dLGN activity $\left({ }^{* *} p=0.0073, t_{(4)}=5.02\right.$, paired $t$ test, $n=$ 5 recordings; Fig. $7 C, D)$. We confirmed that the suppressive effect of blue light continued throughout the recording sessions and did not decline over sequential trials. Although we targeted GABAergic neurons in the thalamic reticular nucleus, it was also possible that virus spread induced ChR2 expression in a subset of GABAergic neurons in the dLGN; however, such unexpected ectopic expression, if any, did not prevent our intended silencing of relay neurons in the dLGN. Using this technique, we monitored the V1 LFP responses to flash stimuli (Fig. 8A). The specific silencing of the dLGN late response suppressed the V1 late response selectively while sparing the V1 early response (Fig. $8 A, B$ ). The late LFP power at each frequency band was reduced significantly to the spontaneous level (Fig. $8 C ; 4-12 \mathrm{~Hz}:{ }^{\star} p=0.025$ light $\mathrm{ON}$ vs light OFF, $t_{(6)}=2.94, \# p=0.024$ vs prestimulus baseline spike rate, $t_{(6)}=$ $2.98 ; 14-30 \mathrm{~Hz}:{ }^{\star} p=0.022, t_{(6)}=3.06, \# p=0.025, t_{(6)}=2.98$; $30-60 \mathrm{~Hz}:{ }^{\star} p=0.011, t_{(6)}=3.57, \# p=0.022, t_{(6)}=3.03$, 

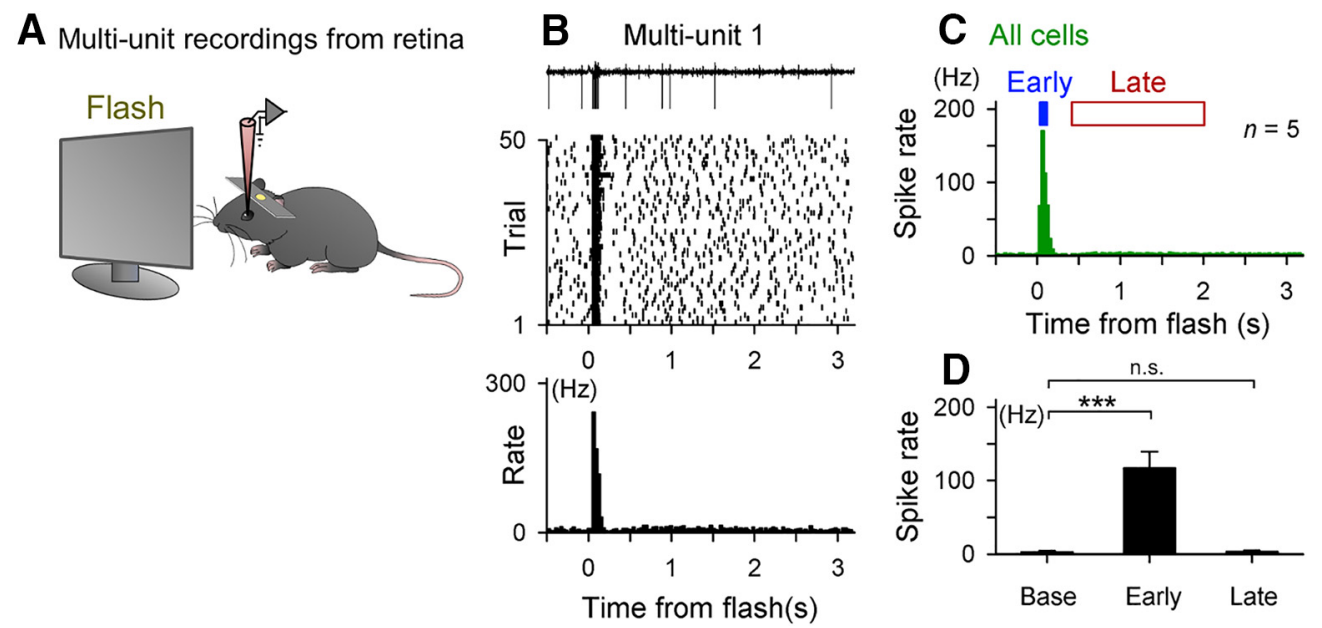

Figure 9. A flash of light fails to induce late spiking in the retina. $\boldsymbol{A}$, In vivo multiunit recordings were acquired from the retina while a light flash was presented 50 times to the ipsilateral eye. $\boldsymbol{B}$, Top, Raw multiunit traces of five representative trials. Middle, Spike raster plots of spike responses. Bottom, Peristimulus time histograms (PSTHs) of the spike response. C, Data were pooled from five recordings from five mice. $D$, Mean \pm SEM of the multiunit spike rates during the time windows of the preflash baseline and the V1 early and late windows of five recordings from five mice. Late spiking is absent from the retinal responses. ${ }^{* *} p=0.0050, t_{(4)}=5.58$, paired $t$ test.

paired $t$ test, $n=7$ mice). Therefore, the $\mathrm{V} 1$ late response depends on late synaptic inputs from the dLGN.

In the feedforward pathway, the dLGN receives driving inputs primarily from retinal ganglion cells. Retinal cells are classified into >50 types of neurons (Enroth-Cugell and Robson, 1966; Boycott and Wassle, 1974; Siegert et al., 2009), some of which may exhibit rebound activity to a brief direct current injection (O'Brien et al., 2002; Mitra and Miller, 2007a, 2007b; Guo et al., 2013). Therefore, we speculated that the retinal rebound spikes may account for the late response identified in the dLGN. We recorded multiunit recordings from the retina in vivo and applied flashes to the same eye (Fig. 9A). The retinal cells responded immediately after the flash with a transient increase in the firing rates (Fig. $9 B, C$ ). On average, this early response had a peak spike rate of $117.2 \pm 48.8 \mathrm{~Hz}$ and a peak latency of $59.0 \pm 13.4 \mathrm{~ms}$ (mean \pm SD of 5 recordings). However, in contrast to our expectation, the retinal cells did not exhibit apparent late spiking (Fig. $9 D, E ; 3.2 \pm 3.7 \mathrm{~Hz}, p=0.18, t_{(4)}=1.62$, paired $t$ test vs the baseline spike rate, $n=5$ recordings from 5 mice). Therefore, the earliest region in which we identified the late response was the dLGN.

\section{Discussion}

In this study, we investigated the functional organization of synaptic inputs that constitute the V1 late response. We discovered that the late response was produced by a balanced increase in the $G_{\mathrm{e}}$ and $G_{\mathrm{i}}$, whereas the dynamics of the $G_{\mathrm{i}}$ were more influential in regulating the spike timing of the neuron. The V1 synaptic activation was driven by the thalamo-cortical activity of the dLGN; however, it did not originate in the retina, indicating that the late response has a different mechanism from that of the early response.

Top-down control by higher-order cortices is often reported to modulate the later part of the sensory response (Zhang et al., 2014; Manita et al., 2015). This feedback activity is likely related by sensory perception. In the case of vision, the ACC is one of the neocortical centers that provide top-down modulation of $\mathrm{V} 1 \mathrm{ac}-$ tivity (Zhang et al., 2014). We demonstrated that the silencing of the ACC reduced the late LFP power of the flash-evoked response; however, its effect was only partial and a large portion of the late response remained. Therefore, a higher-order cor- tex may modulate $\mathrm{V} 1$ through feedback activity but may not be an essential driver of the late response, at least under conditions of anesthesia.

Similar to V1, the dLGN exhibited flash-induced early and late spiking in both anesthetized and awake states. In addition, timeselective optogenetic silencing of the dLGN, which relays visual information directly to $\mathrm{V} 1$, almost completely abolished the V1 late responses. This finding suggested that the generation of $\mathrm{V} 1$ late responses requires thalamic activity. Therefore, a component upstream of the classical feedforward pathway such as the dLGN or retina is the most likely candidate for the neural source of the late response. Moreover, retinal cells showed no late spike responses to flash stimuli. Therefore, we speculated that the V1 late response is likely initiated in the $\mathrm{dLGN}$. In the thalamus, there are several types of relay neurons that emit rebound spikes to direct current stimulation (McCormick and Huguenard, 1992). This rebound spiking is generated through hyperpolarizationinduced deinactivation of low-threshold calcium channels (Grenier et al., 1998; Timofeev and Steriade, 1998). Moreover, recent studies have demonstrated that the intrathalamic interactions control the activity of sensory relay neurons (Halassa et al., 2014; Wimmer et al., 2015). Because our optogenetic manipulation may also silence the activity of thalamic nuclei other than the $\mathrm{dLGN}$, it is possible that the intrathalamic interactions contribute to the V1 late responses.

Although the dLGN is involved in the generation of late response, the generation process itself is likely to be more complicated. The primary sensory thalamus forms a thalamocortical loop with the primary sensory cortex, in which layer 6 cortical neurons give rise to direct excitatory projections back to the primary sensory thalamus (Mease et al., 2014). In the dLGN, this corticothalamic projection contributes up to $40 \%$ of the total synapses, whereas retinal inputs account for only $10 \%$ (Van Horn et al., 2000). Therefore, this thalamocortical loop could also initiate and shape flash-induced late responses.

Thalamic nuclei are thought to control higher-order functions such as cognition and perception because they are positioned to modulate the sensory gain to the cortex efficiently (Rees, 2009; Saalmann and Kastner, 2011). Their activity is enhanced during top-down attention in vision (Chalupa et al., 
1976; Petersen et al., 1985; O'Connor et al., 2002; McAlonan et al., 2008). Furthermore, this effect is preserved across modalities (Frith and Friston, 1996; Morrow and Casey, 2000), as well as across species from rodents to primates (Haynes et al., 2005; McAlonan et al., 2008; Wimmer et al., 2015). Moreover, in the visual pathway, the retinal afferent pathway drives the main sensory response; however, it contributes only $\sim 10 \%$ of the total synaptic inputs received by the dLGN, whereas the remaining projections arrive from various brain regions, including the primary sensory cortices, high-order cortices, and brainstem (Bickford et al., 2000; Saalmann and Kastner, 2011). Therefore, the dLGN serves as the earliest stage in which visual information is actively modulated by multiple brain regions. Considering that late sensory responses may have roles in perceptional processes (Del Cul et al., 2007; Funayama et al., 2015), it is intriguing that the late response in $\mathrm{V} 1$ is initiated at the level of the thalamus.

Sensory activity is abolished when a primary sensory thalamus of the modality is suppressed (Reinhold et al., 2015). Moreover, we reproduced the late response in all tested V1 layer 2/3 neurons when we applied late synaptic conductance via the dynamic clamp technique. This introduces the question of whether the cortical late response merely copies the thalamic response. Even during the sensory response, the majority of the inputs that reach a cortical neuron are derived from the cortical recurrent network (Peters and Payne, 1993). Therefore, the cortical recurrent network amplifies the thalamic input through reverberation-like neuronal activation, but the amplification occurs only in the presence of thalamic activity. Consistent with this idea, the late response of the dLGN was smaller than the early response (Fig. $5 B$ ), whereas in $\mathrm{V} 1$, the late response was comparable or even larger than the early response (Fig. $1 B, D, E$ ). Therefore, the late response is more likely subject to recurrent amplification. Moreover, both excitatory and inhibitory synaptic inputs occurred in V1 layer 2/3 neurons during the late response and were balanced instantaneously on average. This coordinated synaptic balance suggests that a local cortical circuit maintains the late responses.

To our knowledge, this study is the first to demonstrate a thalamocortical component of the late visual response in V1. However, it remains unknown whether thalamic relay neurons generate the late response or if intrathalamic or other circuit interactions are involved. Additional studies are necessary to determine how thalamocortical late inputs interact with feedback inputs from higher-order cortices.

\section{References}

Ban H, Yamamoto H (2013) A non-device-specific approach to display characterization based on linear, nonlinear, and hybrid search algorithms. J Vis 13:20. CrossRef Medline

Benucci A, Frazor RA, Carandini M (2007) Standing waves and traveling waves distinguish two circuits in visual cortex. Neuron 55:103-117. CrossRef Medline

Bickford ME, Ramcharan E, Godwin DW, Erişir A, Gnadt J, Sherman SM (2000) Neurotransmitters contained in the subcortical extraretinal inputs to the monkey lateral geniculate nucleus. J Comp Neurol 424: 701-717. CrossRef Medline

Boycott BB, Wässle H (1974) The morphological types of ganglion cells of the domestic cat's retina. J Physiol 240:397-419. CrossRef Medline

Brainard DH (1997) The Psychophysics Toolbox. Spat Vis 10:433-436. CrossRef Medline

Chalupa LM, Coyle RS, Lindsley DB (1976) Effect of pulvinar lesions on visual pattern discrimination in monkeys. J Neurophysiol 39:354-369. Medline

Dale AM, Sereno MI (1993) Improved localization of cortical activity by combining EEG and MEG with MRI cortical surface reconstruction: a linear approach. J Cogn Neurosci 5:162-176. CrossRef Medline

Dale AM, Fischl B, Sereno MI (1999) Cortical surface-based analysis. I. Seg- mentation and surface reconstruction. Neuroimage 9:179-194. CrossRef Medline

Dale AM, Liu AK, Fischl BR, Buckner RL, Belliveau JW, Lewine JD, Halgren E (2000) Dynamic statistical parametric mapping: combining fMRI and MEG for high-resolution imaging of cortical activity. Neuron 26:55-67. CrossRef Medline

Del Cul A, Baillet S, Dehaene S (2007) Brain dynamics underlying the nonlinear threshold for access to consciousness. PLoS Biol 5:e260. CrossRef Medline

Deweese MR, Zador AM (2004) Shared and private variability in the auditory cortex. J Neurophysiol 92:1840-1855. CrossRef Medline

Dick AO (1974) Iconic memory and its relation to perceptual processing and other memory mechanisms. Percept Psychophysiol 16:575-596. CrossRef

Engel AK, Fries P, Singer W (2001) Dynamic predictions: oscillations and synchrony in top-down processing. Nat Rev Neurosci 2:704-716. CrossRef Medline

Enroth-Cugell C, Robson JG (1966) The contrast sensitivity of retinal ganglion cells of the cat. J Physiol 187:517-552. CrossRef Medline

Felleman DJ, Van Essen DC (1991) Distributed hierarchical processing in the primate cerebral cortex. Cereb Cortex 1:1-47. CrossRef Medline

Fischl B, Sereno MI, Tootell RB, Dale AM (1999) High-resolution intersubject averaging and a coordinate system for the cortical surface. Hum Brain Mapp 8:272-284. CrossRef Medline

Frith CD, Friston KJ (1996) The role of the thalamus in "top down" modulation of attention to sound. Neuroimage 4:210-215. CrossRef Medline

Funayama K, Minamisawa G, Matsumoto N, Ban H, Chan AW, Matsuki N, Murphy TH, Ikegaya Y (2015) Neocortical rebound depolarization enhances visual perception. PLoS Biol 13:e1002231. CrossRef Medline

Gilbert CD, Li W (2013) Top-down influences on visual processing. Nat Rev Neurosci 14:350-363. CrossRef Medline

Gramfort A, Luessi M, Larson E, Engemann DA, Strohmeier D, Brodbeck C, Parkkonen L, Hämäläinen MS (2014) MNE software for processing MEG and EEG data. Neuroimage 86:446-460. CrossRef Medline

Gregoriou GG, Gotts SJ, Zhou H, Desimone R (2009) High-frequency, long-range coupling between prefrontal and visual cortex during attention. Science 324:1207-1210. CrossRef Medline

Grenier F, Timofeev I, Steriade M (1998) Leading role of thalamic over cortical neurons during postinhibitory rebound excitation. Proc Natl Acad Sci U S A 95:13929-13934. CrossRef Medline

Guillery RW, Harting JK (2003) Structure and connections of the thalamic reticular nucleus: Advancing views over half a century. J Comp Neurol 463:360-371. CrossRef Medline

Guo T, Tsai D, Morley JW, Suaning GJ, Lovell NH, Dokos S (2013) Cellspecific modeling of retinal ganglion cell electrical activity. Conf Proc IEEE Eng Med Biol Soc 2013:6539-6542. CrossRef Medline

Haider B, Duque A, Hasenstaub AR, McCormick DA (2006) Neocortical network activity in vivo is generated through a dynamic balance of excitation and inhibition. J Neurosci 26:4535-4545. CrossRef Medline

Halassa MM, Siegle JH, Ritt JT, Ting JT, Feng G, Moore CI (2011) Selective optical drive of thalamic reticular nucleus generates thalamic bursts and cortical spindles. Nat Neurosci 14:1118-1120. CrossRef Medline

Halassa MM, Chen Z, Wimmer RD, Brunetti PM, Zhao S, Zikopoulos B, Wang F, Brown EN, Wilson MA (2014) State-dependent architecture of thalamic reticular subnetworks. Cell 158:808-821. CrossRef Medline

Harrison SA, Tong F (2009) Decoding reveals the contents of visual working memory in early visual areas. Nature 458:632-635. CrossRef Medline

Haynes JD, Deichmann R, Rees G (2005) Eye-specific effects of binocular rivalry in the human lateral geniculate nucleus. Nature 438:496-499. CrossRef Medline

Higley MJ, Contreras D (2006) Balanced excitation and inhibition determine spike timing during frequency adaptation. J Neurosci 26:448-457. CrossRef Medline

Hofer SB, Ko H, Pichler B, Vogelstein J, Ros H, Zeng H, Lein E, Lesica NA, Mrsic-Flogel TD (2011) Differential connectivity and response dynamics of excitatory and inhibitory neurons in visual cortex. Nat Neurosci 14:1045-1052. CrossRef Medline

Ishikawa D, Matsumoto N, Sakaguchi T, Matsuki N, Ikegaya Y (2014) Operant conditioning of synaptic and spiking activity patterns in single hippocampal neurons. J Neurosci 34:5044-5053. CrossRef Medline

Jia H, Rochefort NL, Chen X, Konnerth A (2010) Dendritic organization of 
sensory input to cortical neurons in vivo. Nature 464:1307-1312. CrossRef Medline

Liu BH, Li YT, Ma WP, Pan CJ, Zhang LI, Tao HW (2011) Broad inhibition sharpens orientation selectivity by expanding input dynamic range in mouse simple cells. Neuron 71:542-554. CrossRef Medline

Manita S, Suzuki T, Homma C, Matsumoto T, Odagawa M, Yamada K, Ota K, Matsubara C, Inutsuka A, Sato M, Ohkura M, Yamanaka A, Yanagawa Y, Nakai J, Hayashi Y, Larkum ME, Murayama M (2015) A top-down cortical circuit for accurate sensory perception. Neuron 86:1304-1316. CrossRef Medline

McAlonan K, Cavanaugh J, Wurtz RH (2008) Guarding the gateway to cortex with attention in visual thalamus. Nature 456:391-394. CrossRef Medline

McCormick DA, Huguenard JR (1992) A model of the electrophysiological properties of thalamocortical relay neurons. J Neurophysiol 68:13841400. Medline

Mease RA, Krieger P, Groh A (2014) Cortical control of adaptation and sensory relay mode in the thalamus. Proc Natl Acad Sci U S A 111:67986803. CrossRef Medline

Minamisawa G, Funayama K, Matsuki N, Ikegaya Y (2011) Intact internal dynamics of the neocortex in acutely paralyzed mice. J Physiol Sci 61:343348. CrossRef Medline

Mitra P, Miller RF (2007a) Normal and rebound impulse firing in retinal ganglion cells. Vis Neurosci 24:79-90. CrossRef Medline

Mitra P, Miller RF (2007b) Mechanism underlying rebound excitation in retinal ganglion cells. Vis Neurosci 24:709-731. CrossRef Medline

Mohajerani MH, Chan AW, Mohsenvand M, LeDue J, Liu R, McVea DA, Boyd JD, Wang YT, Reimers M, Murphy TH (2013) Spontaneous cortical activity alternates between motifs defined by regional axonal projections. Nat Neurosci 16:1426-1435. CrossRef Medline

Moore T, Armstrong KM (2003) Selective gating of visual signals by microstimulation of frontal cortex. Nature 421:370-373. CrossRef Medline

Morrow TJ, Casey KL (2000) Attention-related, cross-modality modulation of somatosensory neurons in primate ventrobasal (VB) thalamus. Somatosens Mot Res 17:133-144. CrossRef Medline

Munneke J, Heslenfeld DJ, Theeuwes J (2010) Spatial working memory effects in early visual cortex. Brain Cogn 72:368-377. CrossRef Medline

Niell CM, Stryker MP (2008) Highly selective receptive fields in mouse visual cortex. J Neurosci 28:7520-7536. CrossRef Medline

O’Brien BJ, Isayama T, Richardson R, Berson DM (2002) Intrinsic physiological properties of cat retinal ganglion cells. J Physiol 538:787-802. CrossRef Medline

O'Connor DH, Fukui MM, Pinsk MA, Kastner S (2002) Attention modulates responses in the human lateral geniculate nucleus. Nat Neurosci 5:1203-1209. CrossRef Medline

Ohki K, Chung S, Ch'ng YH, Kara P, Reid RC (2005) Functional imaging with cellular resolution reveals precise micro-architecture in visual cortex. Nature 433:597-603. CrossRef Medline

Peters A, Payne BR (1993) Numerical relationships between geniculocortical afferents and pyramidal cell modules in cat primary visual cortex. Cereb Cortex 3:69-78. CrossRef Medline

Petersen SE, Robinson DL, Keys W (1985) Pulvinar nuclei of the behaving rhesus monkey: visual responses and their modulation. J Neurophysiol 54:867-886. Medline

Poulet JF, Petersen CC (2008) Internal brain state regulates membrane potential synchrony in barrel cortex of behaving mice. Nature 454:881-885. CrossRef Medline

Priebe NJ, Ferster D (2008) Inhibition, spike threshold, and stimulus selectivity in primary visual cortex. Neuron 57:482-497. CrossRef Medline

Purves D, Lotto RB, Williams SM, Nundy S, Yang Z (2001) Why we see things the way we do: evidence for a wholly empirical strategy of vision. Philos Trans R Soc Lond B Biol Sci 356:285-297. CrossRef Medline

Rees G (2009) Visual attention: the thalamus at the centre? Curr Biol 19: R213-R214. CrossRef Medline
Reinhold K, Lien AD, Scanziani M (2015) Distinct recurrent versus afferent dynamics in cortical visual processing. Nat Neurosci 18:1789-1797. CrossRef Medline

Ren M, Yoshimura Y, Takada N, Horibe S, Komatsu Y (2007) Specialized inhibitory synaptic actions between nearby neocortical pyramidal neurons. Science 316:758-761. CrossRef Medline

Reynolds JH, Pasternak T, Desimone R (2000) Attention increases sensitivity of V4 neurons. Neuron 26:703-714. CrossRef Medline

Roelfsema PR, Lamme VA, Spekreijse H (1998) Object-based attention in the primary visual cortex of the macaque monkey. Nature 395:376-381. CrossRef Medline

Saalmann YB, Kastner S (2009) Gain control in the visual thalamus during perception and cognition. Curr Opin Neurobiol 19:408-414. CrossRef Medline

Saalmann YB, Kastner S (2011) Cognitive and perceptual functions of the visual thalamus. Neuron 71:209-223. CrossRef Medline

Sherman SM (2001) Tonic and burst firing: dual modes of thalamocortical relay. Trends Neurosci 24:122-126. CrossRef Medline

Siegert S, Scherf BG, Del Punta K, Didkovsky N, Heintz N, Roska B (2009) Genetic address book for retinal cell types. Nat Neurosci 12:1197-1204. CrossRef Medline

Supèr H, Spekreijse H, Lamme VA (2001) A neural correlate of working memory in the monkey primary visual cortex. Science 293:120-124. CrossRef Medline

Takahashi N, Sasaki T, Matsumoto W, Matsuki N, Ikegaya Y (2010) Circuit topology for synchronizing neurons in spontaneously active networks. Proc Natl Acad Sci U S A 107:10244-10249. CrossRef Medline

Taulu S, Kajola M, Simola J (2004) Suppression of interference and artifacts by the signal space separation method. Brain Topography 16:269-275.

Taulu S, Simola J (2006) Spatiotemporal signal space separation method for rejecting nearby interference in MEG measurements. Phys Med Biol $51: 1759$.

Timofeev I, Steriade M (1998) Cellular mechanisms underlying intrathalamic augmenting responses of reticular and relay neurons. J Neurophysiol 79:2716-2729. Medline

Van Horn SC, Erisir A, Sherman SM (2000) Relative distribution of synapses in the A-laminae of the lateral geniculate nucleus of the cat. J Comp Neurol 416:509-520. Medline

von Stein A, Chiang C, König P (2000) Top-down processing mediated by interareal synchronization. Proc Natl Acad Sci U S A 97:14748-14753. CrossRef Medline

Vong L, Ye C, Yang Z, Choi B, Chua S Jr, Lowell BB (2011) Leptin action on GABAergic neurons prevents obesity and reduces inhibitory tone to POMC neurons. Neuron 71:142-154. CrossRef Medline

Wehr M, Zador AM (2003) Balanced inhibition underlies tuning and sharpens spike timing in auditory cortex. Nature 426:442-446. CrossRef Medline

Weyand TG, Boudreaux M, Guido W (2001) Burst and tonic response modes in thalamic neurons during sleep and wakefulness. J Neurophysiol 85:1107-1118. Medline

Wimmer RD, Schmitt LI, Davidson TJ, Nakajima M, Deisseroth K, Halassa MM (2015) Thalamic control of sensory selection in divided attention. Nature 526:705-709. CrossRef Medline

Yoshimura Y, Callaway EM (2005) Fine-scale specificity of cortical networks depends on inhibitory cell type and connectivity. Nat Neurosci 8:1552-1559. CrossRef Medline

Zhang S, Xu M, Kamigaki T, Hoang Do JP, Chang WC, Jenvay S, Miyamichi K, Luo L, Dan Y (2014) Selective attention: long-range and local circuits for top-down modulation of visual cortex processing. Science 345:660665. CrossRef Medline

Zingg B, Hintiryan H, Gou L, Song MY, Bay M, Bienkowski MS, Foster NN, Yamashita S, Bowman I, Toga AW, Dong HW (2014) Neural networks of the mouse neocortex. Cell 156:1096-1111. CrossRef Medline 